\title{
Ability of Box-Jenkins Models to Estimate of Reference Potential Evapotranspiration (A Case Study: Mehrabad Synoptic Station, Tehran, Iran)
}

\author{
Mohammad Valipour \\ Department of Irrigation and Drainage Engineering, College of Abureyhan, University of Tehran, Pakdasht, \\ Tehran, Iran,
}

\begin{abstract}
The evapotranspiration rate has a vital role in agricultural water management. In this paper, ability of Box-Jenkins models in forecasting the reference potential evapotranspiration is estimated. For this purpose meteorological data of Mehrabad synoptic station in Tehran was selected. Using this data and according to eight famous evapotranspiration equations amounts of evapotranspiration were forecasted by Box-Jenkins models. Equations of reference potential evapotranspiration that used in this study include: FAO Penman Monteith (FPM), FAO Blaney Criddle (FBC), Turc, FAO Radiation Macking (FRM), Priestley Taylor (PT), Hargreaves Samani (HS), Thornthwaite (TW), and Corrected Jensen Haise (CJH). A box-Jenkins model has found a widespread application in many practical sciences. In addition, evapotranspiration forecasting is done by some methods such as remote sensing, genetic algorithm, and artificial neural networks. On the other hand, application of both Box-Jenkins models simultaneously in order to compare their ability in forecast of evapotranspiration has not been carried out in previous researches. Therefore, this paper attempts to forecast the evapotranspiration and meteorological data by using Box-Jenkins models while increasing the number of parameters in order to increase the forecast accuracy to five parameters and comparing them. By comparing root mean square error of the models, it was determined that Box-Jenkins models are appropriate approaches to evapotranspiration forecasting.
\end{abstract}

Keywords: Box-Jenkins models, evapotranspiration, meteorological data

\section{Introduction}

More accurate estimation of reference potential evapotranspiration is significantly important in water resources management and crop pattern design. In this study, Box-Jenkins models have forecast evapotranspiration and meteorological data. After publishing the paper of Box and Jenkins (1976), Box-Jenkins models became one general time series model of hydrological forecasting. These models include: Auto Regressive Integrated Moving Average (ARIMA), Auto Regressive Moving Average (ARMA), Auto Regressive (AR), and Moving Average (MA). Access to basic information requires integration from the series (for a continuous series) or calculating all of differences the series (for a continuous series). Since the constant of integration in derivation or differences deleted, the probability of using these amount or middle amount in this process is not possible. Therefore, ARIMA models are non-static and cannot be used to reconstruct the missing data. However, these models are very useful for forecasting changes in a process (Karamouz and Araghinejad, 2012). Models of time series analysis (Box-Jenkins models) in various fields of hydrology and estimating evapotranspiration in irrigation schedule are widely applied, which some of them will be described in the following.

Kang et al. (2003) used of crop coefficient and ratio of transpiration to evapotranspiration of winter wheat and maize in a semi-humid region. Their results helped to the precise planning and efficient management of irrigation for these crops in this region. Casa et al. (2000) estimated evapotranspiration from a field of linseed in central Italy. They were found that daily evapotranspiration could be estimated from partially incomplete Bowen ratio data on a continuous basis throughout the growing season. Granger (2000) used from NOAAAVHRR and LANDSAT images to estimates of evapotranspiration in the Gediz basin, Turkey. The results from both remote sensing platforms showed evapotranspiration rates in the range of $2.5-4.5 \mathrm{~mm} / \mathrm{d}$ for the basin. Pereira (2004), using the Priestley-Taylor parameter and the decoupling factor estimated reference evapotranspiration. Silva et al. (2010) estimated reference evapotranspiration using numerical weather forecast data in central Chile. They were found that the estimation of reference evapotranspiration based on MOScorrected weather variables is usually the most effective method to estimate reference evapotranspiration. Alexandris et al. (2006) estimated daily reference evapotranspiration by the "Copais" approach. The proposed empirical model was a useful tool for routine daily reference evapotranspiration estimations. Douglas et al. (2009) using Penman Monteith (PM), Turc (Tc), and Priestley Taylor (PT) methods estimated potential evapotranspiration (PET) for Florida land cover types. Under such PET conditions, annually aggregated Tc and 
PT methods perform comparably and outperform the PM method, possibly due to the sensitivity of the PM method to the limited transferability of previously determined model parameters. At a daily scale, the PT performance appears to be superior to the other two methods for estimating PET for a variety of land covers in Florida. Alexandris and Kerkides (2003) presented a new empirical formula for hourly estimations of reference evapotranspiration successfully. Xu et al. (2006) analyzed spatial distribution and temporal trend of reference evapotranspiration and pan evaporation in Changjiang (Yangtze River) catchment. Sensitivity analysis showed that the reference evapotranspiration was most sensitive to the net total radiation, followed by relative humidity, air temperature and wind speed. Yin et al. (2008), estimated reference crop evapotranspiration in China using radiation calibration of FAO56 Penman Monteith model. The calibrated net radiation served as the basis to estimate ETo accurately, which would be overestimated by about $27 \%$ if no local calibration is performed on the FAO56 Penman-Monteith model in China. The average ETo was $769 \mathrm{~mm} /$ year based on calibrated radiation model in China during 1971-2000. Kadlec (2006) studied water temperature and evapotranspiration in surface flow wetlands in hot arid climate. The results showed that evapotranspiration was higher than that predicted for a balance condition, because of the warmth of the incoming water. It was less than that predicted for a grass crop. Using Shuttleworth-Wallace model and NOAA-AVHRR NDVI data, Zhou et al. (2006), estimated potential evapotranspiration to feed a distributed hydrological model over the Mekong River basin. Kim and Kim (2008) used neural networks and genetic algorithm approach for nonlinear evaporation and evapotranspiration modeling successfully. Sumner and Jacobs (2005) surveyed utility of Penman Monteith, Priestley Taylor, reference evapotranspiration, and pan evaporation methods to estimate pasture evapotranspiration. The results showed that relations among PM, PT, and ETo methods and actual evapotranspiration (Eta) can provide estimates of Eta in other, environmentally similar, pasture settings for which meteorological and green-leaf area index (LAI) data can be obtained or estimated. Using remotely sensed solar radiation data, Bois et al. (2008) estimated reference evapotranspiration at a daily time step. The results suggested that using satellite-sensed solar radiation might improve eference evapotranspiration estimates for areas where air temperature is the only available record at ground level. M. Baareh et al. (2006) used the artificial neural network and Auto-Regression (AR) models to the river flow forecasting problem. A comparative study of both ANN and the AR conventional model networks indicated that the artificial neural networks performed better than the AR model. They showed that ANN models can be used to train and forecast the daily flows of the Black Water River near Dendron in Virginia and the Gila River near Clifton in Arizona. Xiong and M. O'connor (2002) used four different error-forecast updating models, autoregressive (AR), autoregressive-threshold (AR-TS), fuzzy autoregressive-threshold (FU-AR-TS), and artificial neural network (ANN) to the real-time river flow forecasting. They found that all of these four updating models are very successful in improving the flow forecast accuracy. Chenoweth et al. (2000) estimated the ARMA model parameters using neural networks. Their result showed that the ability of neural networks to accurately identify the order of an ARMA model was much lower than reported by previous researchers, and is especially low for time series with fewer than 100 observations. Using forecasting of hydrologic time series with ridge regression in feature space, Yu and Liong (2007) showed that the training speed in data mining method was very much faster than ARIMA model. See and Abrahart (2001) used of data fusion for hydrological forecasting. Their results showed that using of data fusion methodologies for ANN, fuzzy logic, and ARMA models accuracy of forecasting would increase. Using hybrid approaches, Srinivas and Srinivasan (2000) improved the accuracy of AR model parameters for annual streamflows. Using the Fourier coefficients, Ludlow and Enders (2000) estimated the ARMA model parameters with a relatively good accuracy. Chenoweth et al. (2004) estimated the ARMA model parameters using the Hilbert coefficients. Their results showed that the Hilbert coefficients are considered a useful tool for estimating ARMA model parameters. Balaguer et al. (2008) used the method of time delay neural network (TDNN) and ARMA model to forecast asking for help in support centers for crisis management. The obtained correlation results for TDNN model and ARMA were 0.88 and 0.97, respectively. This study confirmed the superiority of ARMA model to the TDNN. Toth et al. (2000) used the artificial neural network and ARMA models to forecast rainfall. The results show the success of both short-term rainfallforecasting models for forecast floods in real time. Mohammadi et al. (2005) forecast Karaj reservoir inflow using data of melting snow and artificial neural network and ARMA methods, and regression analysis. $60 \%$ of inflow in dam happens between Aprils until June, so forecasting the inflow in this season is very important for dam's performance. The highest inflows were in the spring due to the snow melt caused by draining in threshold winter. The results showed that artificial neural network has lower significant errors as compared with other methods. Mohammadi et al. (2006) in other research estimated parameters of an ARMA model for river flow forecasting using goal programming. Their results showed that the goal programming is a precise and effective method for estimating ARMA model parameters for forecasting inflow. Valipour et al. (2012) estimated parameters of ARMA and ARIMA models and compare their ability for inflow forecasting. By comparing root mean square error of the model, it was determined that ARIMA model can forecast inflow to the Dez reservoir from 12 months ago with lower error than the ARMA model. 
Therefore, considering the above mentioned performed researches, we can know the efficacy of BoxJenkins models in forecasting field and hydrologic sampling as compared with another statistic models such as usual linear and nonlinear regression. Furthermore, concurrent use of Box-Jenkins models has not been done in previous researches to compare them. This study aims to estimate reference potential evapotranspiration using Box-Jenkins models, by increasing the number of parameters to evaluate the accuracy of forecast to five parameters, according to Mehrabad synoptic station data.

\section{Materials And Methods}

In Mehrabad synoptic station located at Tehran city in Iran. The station ranges between $35^{\circ}, 41^{\prime}$ North latitude and $51^{\circ}, 19^{\prime}$ east longitude and is located in center of Tehran. The elevation of station is 1190.8 meter above sea level. In order to estimate reference potential evapotranspiration at the monthly scale, the station's meteorological data period from 1951-2000 has been gathered. Actually, the used data involved 3600 data that began from Janury1951and end in December 2000, include: mean temperature $\left(\mathrm{T}_{\text {mean }}\right)$, wind speed (U), maximum temperature $\left(T_{\max }\right)$, minimum temperature $\left(T_{\min }\right)$, dew point temperature $\left(T_{d}\right)$, and sunshine hours recorded (n). Figure 1 shows position of Mehrabad synoptic station.

In this study, Box-Jenkins models were used for estimate reference potential evapotranspiration individually. These models include: Auto Regressive Integrated Moving Average (ARIMA), Auto Regressive Moving Average (ARMA), Auto Regressive (AR), and Moving Average (MA). For this purpose used MINITAB software to run of all Box-Jenkins models. In addition in this research used from eight evapotranspiration equations include: FAO Penman Monteith (FPM), FAO Blaney Criddle (FBC), Turc, FAO Radiation Macking (FRM), Priestley Taylor (PT), Hargreaves Samani (HS), Thornthwaite (TW), and Corrected Jensen Haise (CJH). Finally by two methods ability of Box-Jenkins models to estimate of reference potential evapotranspiration were surveyed. In first method, using meteorological data amount of evapotranspiration obtained to eache equation for first 45 years data (1951-1995). This was calibration period for Box-Jenkins models. Then using this obtained evapotranspiration data, amount of evapotranspiration forecasted for 5 last years (1996-2000) and results compared with obtained data for each equation in 5 last years. In second method, using first 45 years meteorological data, amount of each six meteorological data (mean temperature, wind speed, maximum temperature, minimum temperature, dew point temperature, and sunshine hours recorded) forecasted for 5 last years (1996-2000) and then using these obtained data, amount of evapotranspiration calculated for each equation. In fact, in first method, calculations are performed primary and then forecasting is done. In second method, forecasting are performed primary and then calculations is done.

\section{Results And Discussion}

After running more than 5000 structures in MINITAB software for each method, table 1 shows obtained results for meteorological data and table 2 shows obtained results for reference potential evapotranspiration.

According to obtained results from Valipour et al (2012) for increase parameters of Box-jenkins models to 4 or 5 , accuracy of forecasting increase which this is observable in tables 1 and 2, for example $\operatorname{ARIMA}(2,0,0)(5,1,3)_{12}$ in table 2 . The aim of this research is not compare equations of reference potential evapotranspiration. Because according to the previous researches each of the eight discussed equations is better for some climate conditions. If for desired area, the best equation of reference potential evapotranspiration were specified, according table 2 the best structure is selected else using climatology of desired area, the best equation for this conditions is selected and then from table 2 the best structure of Box-Jenkins models is observable. Table 2 shows that accuracy of methods 1 and 2 is similar but for more accurate for example in PT equation method 2 is superior than method 1 (RMSE $=0.597$ than RMSE $=0.688$ ). According to the figures 2 to 4 specifics that ARIMA, ARMA, and AR models are appropriate tools to forecasting meteorological data and reference potential evapotranspiratoin (Both methods), but ARIMA model is more accurate into the two other models.

\section{Conclusion}

In this paper, ability of Box-Jenkins models is compared in estimating reference potential evapotranspiration. Monthly meteorological data for a period of 45 years were gathered from Mehrabad synoptic station and used for calibration of models. 


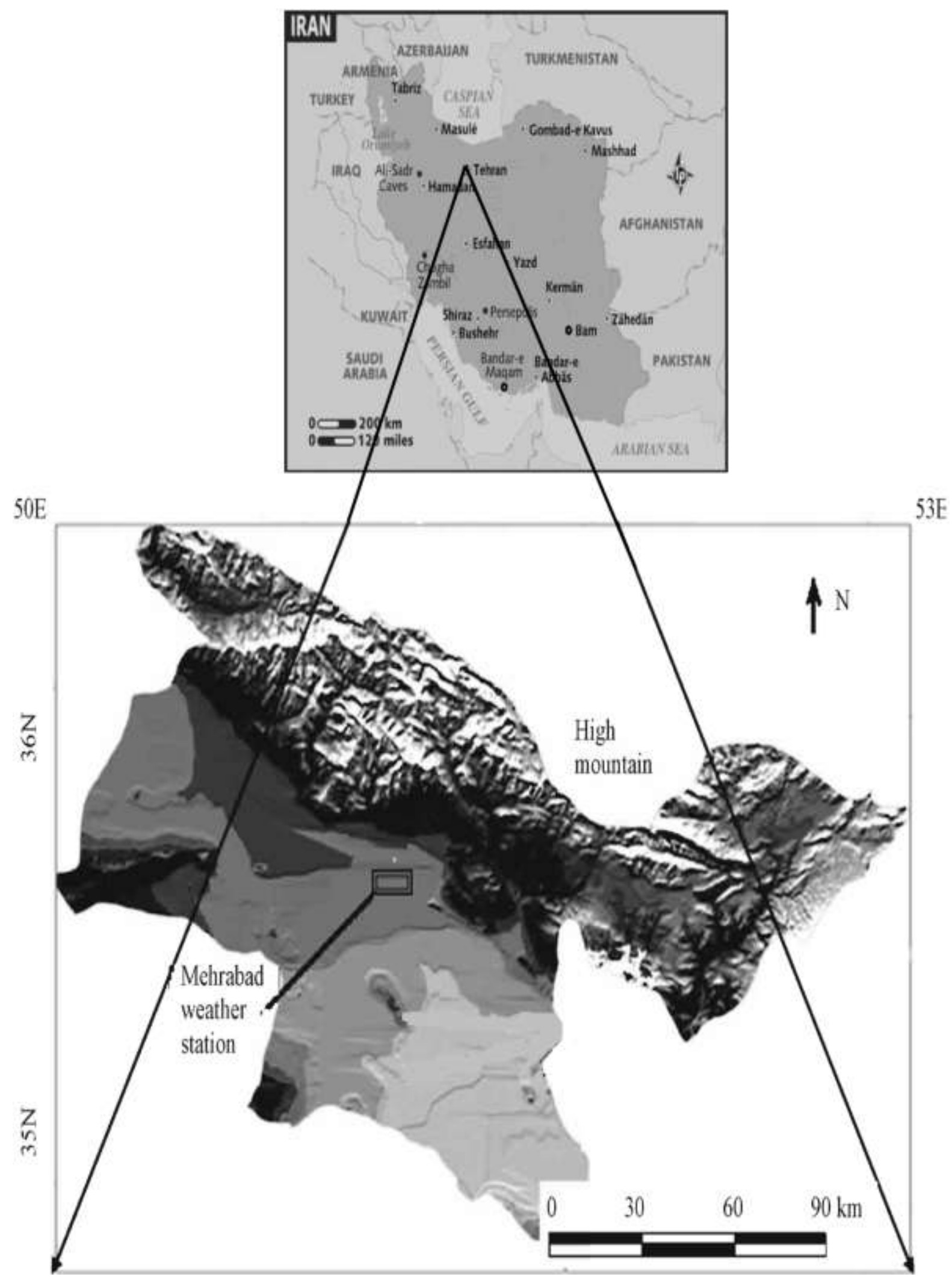

Fig. 1: A DEM of the Mehrabad synoptic station 
Ability of Box-Jenkins Models to Estimate of Reference Potential Evapotranspiration (A Case Study:

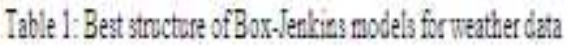

\begin{tabular}{|c|c|c|c|c|c|c|c|c|}
\hline Tieather cata & ARIA & RMSE & ARULA & RVISE & $A R$ & RMSE & MA & RISE \\
\hline$I_{\operatorname{sen}}(0)$ & 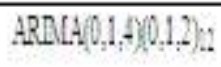 & 1.697 & ARUIA(2) (2:1):L & 1.861 & $A R(+(0)):$ & 1764 & $\mathrm{MA}(+15)_{2}$ & 5778 \\
\hline $\operatorname{tg}(0)$ & ARRAA(0,1, $)(0,1,1)$ : & 1.400 & ARMLA $(2,+(3,1), 2$ & 1776 & $A R(+4)(5): 2$ & 1618 & $M A(-5) \ldots$ & 5398 \\
\hline $\operatorname{Tsm}_{m}(0)$ & 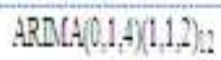 & 1.834 & ARMA $(1,3)(3,2): 2$ & 1864 & $A R(+(5)): 2$ & 2.014 & $M A(+(5)): Z$ & 6.405 \\
\hline$I_{i}(C)$ & 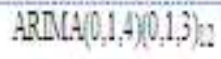 & 3.060 & ARULA(1.4)(2:1):2 & 3.47 & $\mathbb{A R}(+(5): 2$ & 3261 & $\operatorname{MLA}(5): 2$ & 5.173 \\
\hline $\mathrm{e}(\mathrm{kr})$ & ARRLA(0,1, $, 0,1,1):$ & 27.069 & ARUA(1,1)(2:1):2 & 27835 & $A R(5): 2$ & $31: 76$ & MA $(+)(5):$ & $58.30^{\circ}$ \\
\hline$U(m-3)$ & $\operatorname{ARR}(A(1,0,0)(5,1,1))$ & 0.362 & $\operatorname{ARU}(2: 2)(2 ; 1): 2$ & 0.375 & $A R(3 \times 5): 2$ & 0.410 & $\mathrm{MA}(+(5))=$ & 0.639 \\
\hline
\end{tabular}

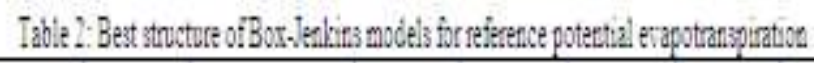

\begin{tabular}{|c|c|c|c|c|c|c|c|c|c|c|c|c|}
\hline Tlezer dats & SRLA & $\begin{array}{l}\text { RUSE } \\
\text { (MAtW }\end{array}$ & $\begin{array}{l}\text { RLEE } \\
\text { MAthow? }\end{array}$ & ARLA & $\begin{array}{l}\text { RUSE } \\
\text { (NAoth) }\end{array}$ & $\begin{array}{l}\text { RUSE } \\
\text { (Mend?) }\end{array}$ & $\Delta R$ & $\begin{array}{l}\text { RUE } \\
\text { (Aletwl]) }\end{array}$ & $\begin{array}{l}\text { RUE } \\
\text { Mend? }\end{array}$ & WH & $\begin{array}{l}\text { BSE } \\
\text { Mlebad: }\end{array}$ & $\begin{array}{l}\text { RISE } \\
\text { Meavd }\end{array}$ \\
\hline FNI & ART $1,(2,1,+1,1)$ & 2521 & 2516 & 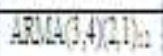 & 0532 & 0.52 & $\operatorname{AR}(t / 5):$ & 0.57 & 0.533 & 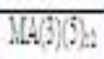 & 182 & \\
\hline 30 & 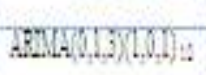 & 066 & 869: & 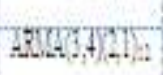 & 0689 & 069 & ART/ $\%$ : & WI! & 015 & $M 2,+(5)=$ & 112 & \\
\hline Jex: & 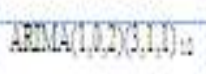 & 287 & 618 & सK(KX) & 0.818 & $0.9^{\circ}$ & ARS $/ 5:$ : & $\mathrm{rm}$ & 0.27 & $M x,+(5)=$ & BKA & 0354 \\
\hline ENL & 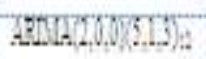 & 6300 & Di: & MVYAIIXII: & $0.30 !$ & $0 \%$ & ART:F? & 0.35 & $0.6 \%$ & MAT) $: \ldots$ & IEII & \\
\hline$\pi$ & 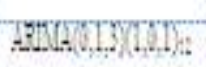 & 6388 & 839 & TRL/1.)IIL & 078 & 8685 & $A M,(2)=$ & Tht & 0,76 & MHYY:L & X9. & \\
\hline E & 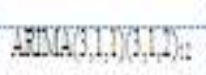 & EIt & DS65 & MRLWWI: & $6 \%$ & $8.5 \%$ & $A, 4, \ldots$ & J65! & $637^{-7}$ & XWYWH & ms & \\
\hline$\pi$ & 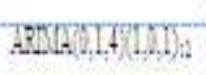 & $24: 2$ & 0.48 & TEYAI,+LII: & 244 & U.FI & AN(t), & VWII & 0.1 .4 & $M A, T, \ldots$ & TWS & \\
\hline $\mathrm{CH}$ & 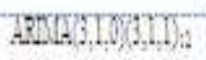 & ER6t & 2886 & ARIMIIYY:-: & 0.65t & $\mathrm{mI}$ & $A(x+1,5)$ & 0.37 & 0.16 & MLIST): & TIK & \\
\hline
\end{tabular}



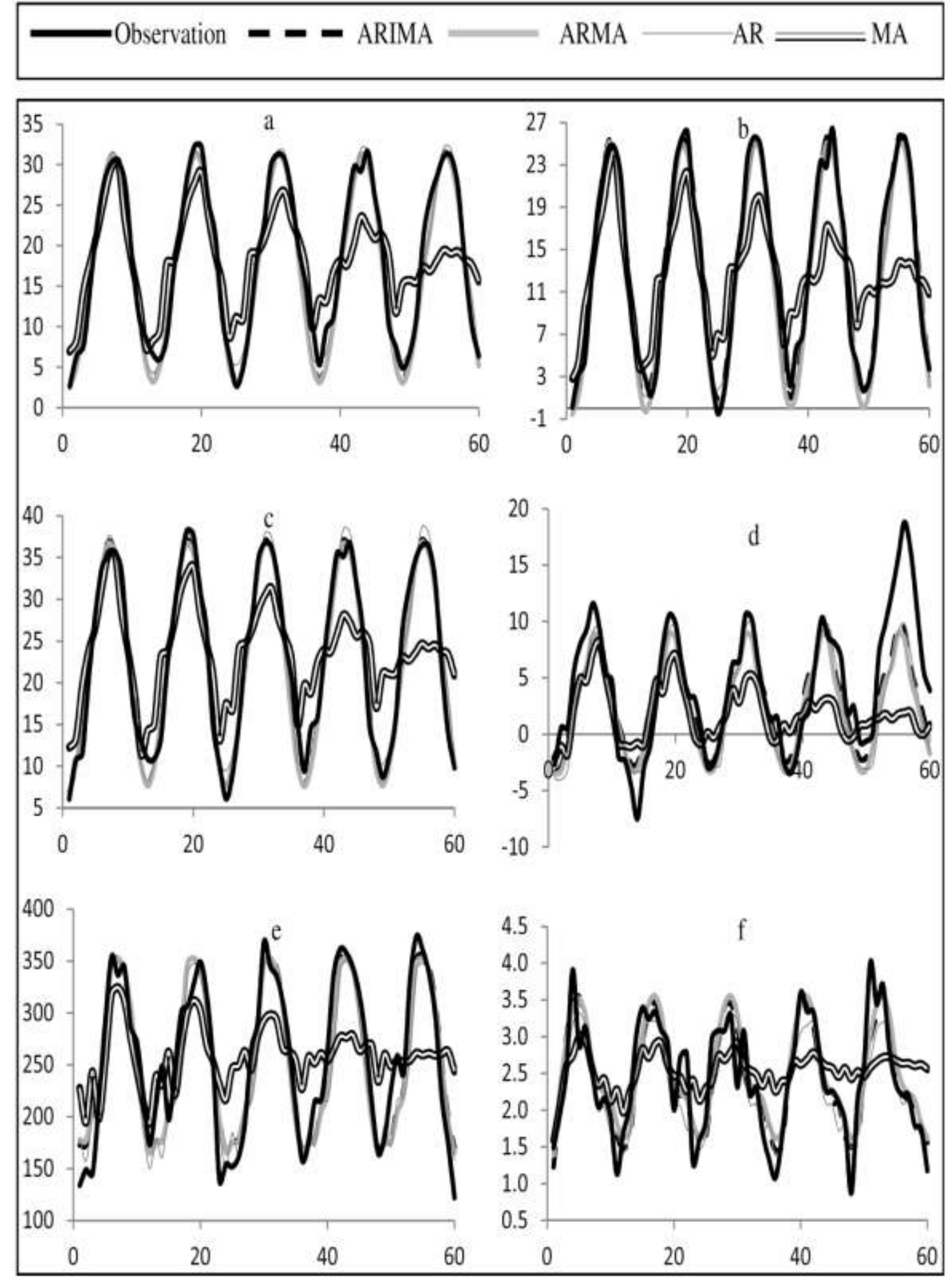

$\mathrm{X}$ axis indicate Time(month) and $\mathrm{Y}$ axis indicate $\mathrm{T}_{\text {mend }}\left({ }^{\circ} \mathrm{C}\right), \mathrm{T}_{\min }\left({ }^{\circ} \mathrm{C}\right), \mathrm{T}_{\max }\left({ }^{\circ} \mathrm{C}\right), \mathrm{T}_{\mathrm{i}}\left({ }^{\circ} \mathrm{C}\right), \mathrm{n}(\mathrm{hr}), \mathrm{U}(\mathrm{m} / \mathrm{s})$, in a-f states, respectively Fig. 2: Meteorological forecasted data for 5 next year 

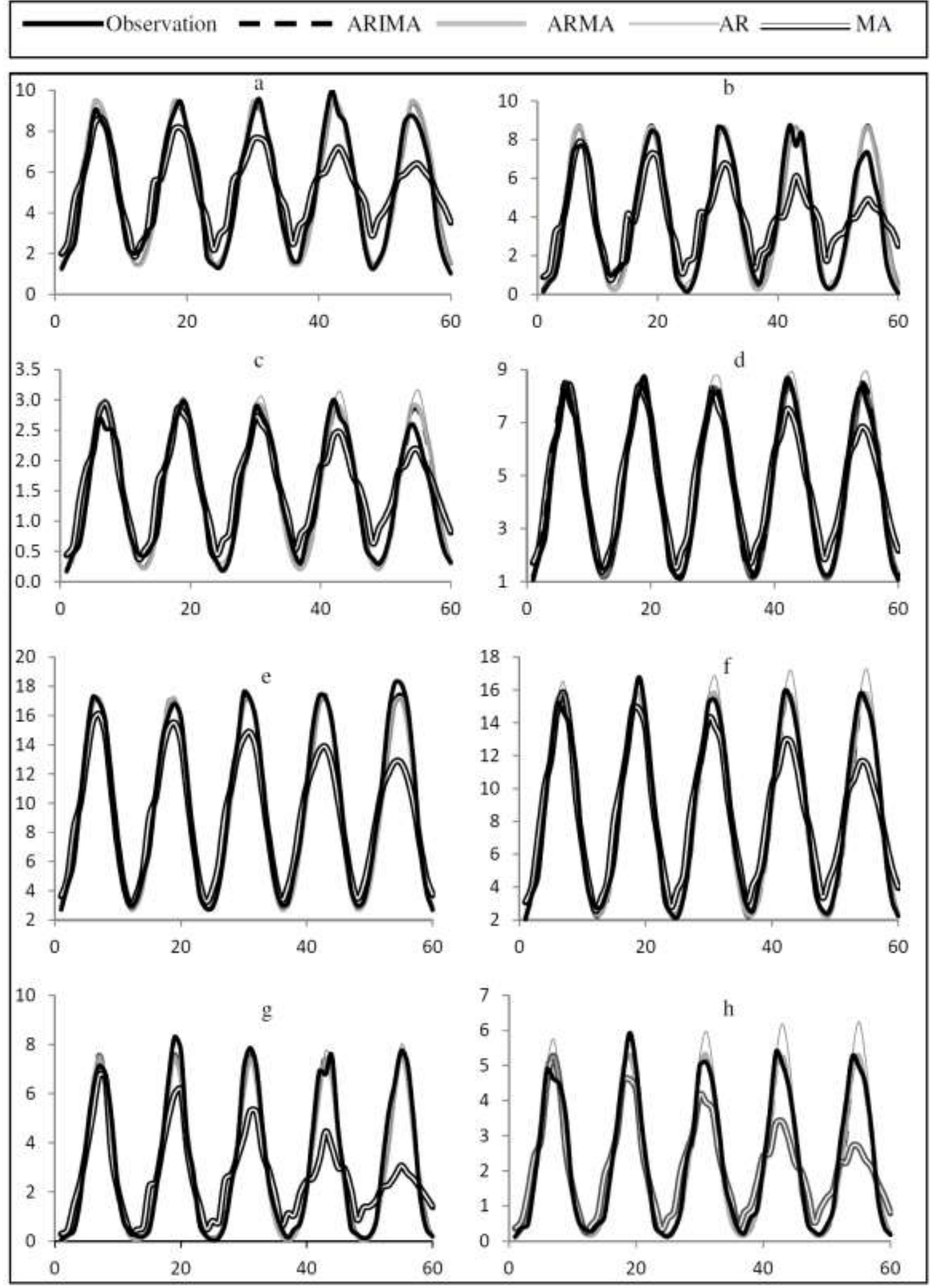

$\mathrm{X}$ axis indicate Time(month) and $\mathrm{Y}$ axis indicate FPM(mm/day), FBC(mm/day), Turc(mm/day), FRM(mm/day), PT(mm/day), HS(mm/day), TW(mm/day ), CJH(mm/day), in a-h states, respectively

Fig. 3: Reference potential evapotranspiration forecasted data for 5 next year using method 1 


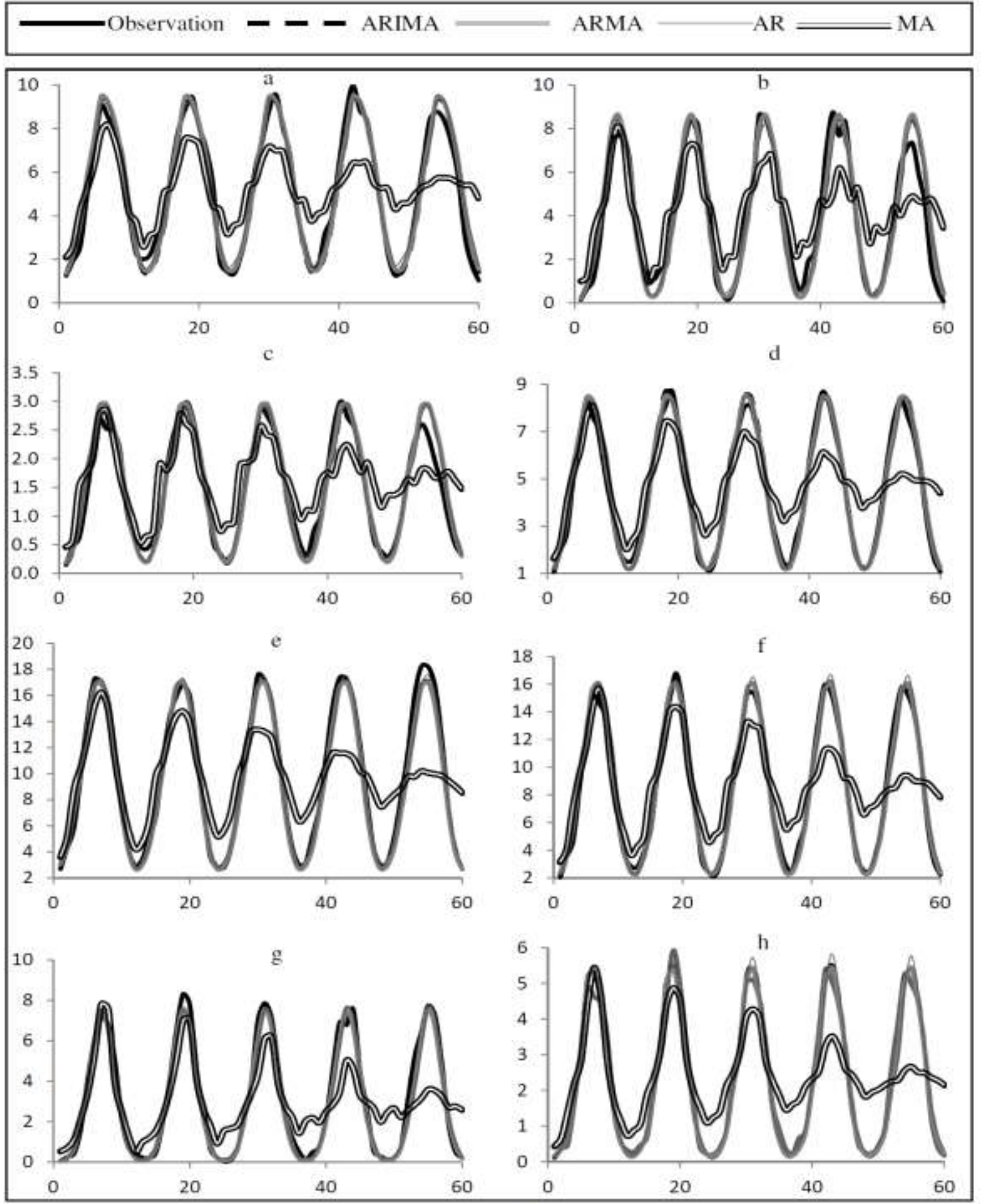

$X$ axis indicate Time(month) and $Y$ axis indicate FPM(mm/day), FBC(mm/day), Turc(mm/day), FRM(mm/day), PT(mm/day), HS(mm/day). TW( $\mathrm{mm} / \mathrm{day}), \mathrm{CJH}(\mathrm{mm} / \mathrm{day})$, in a-h states, respectively

Fig. 4: Reference potential evapotranspiration forecasted data for 5 next year using method 2

Then, the accuracy of forecasting models were investigated by 5 years data. To summarize, it could be concluded that: The accuracy of Box-Jenkins models increased compared to previous studies, due to increase in the number of autoregressive and moving average parameters in these models to five parameters. ARIMA, ARMA, and AR models are appropriate tools to forecasting meteorological data and reference potential evapotranspiratoin.

The ARIMA model has a better performance than ARMA and AR models because it makes time series stationary, in both calibration and forecasting phases. By investigating results, it will be clear that the ARIMA model could be used to forecasting monthly evapotranspiration for the next 60 months. 
V.

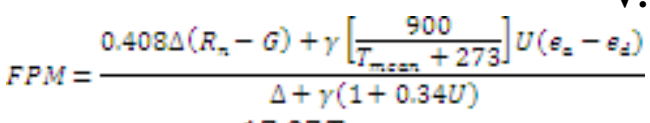

\section{Appendix}

$\Delta=\frac{2504 \exp \left[\frac{17.27 T_{\text {magn }}}{T_{\text {menn }}+237.3}\right]}{\left(T_{\text {mean }}+237.3\right)^{2}}$

$\gamma=0.00163 \frac{P}{\lambda}$

$P=101.3\left(\frac{293-0.0065 Z}{293}\right)^{5.26}$

$\lambda=2.501-\left(2.361 \times 10^{-1}\right) T_{\text {MXEM }}$

$e_{a \mathrm{a}}=\frac{e\left(T_{\mathrm{max}}\right)+e\left(T_{\mathrm{mm}}\right)}{2}$

$\mathrm{e}\left(T_{\max }\right)=0.611 \exp \left(\frac{17.27 T_{\max }}{T_{\max }+2879}\right)$

$\mathrm{e}\left(T_{\text {ming }}\right)=0.611 \exp \left(\frac{17.27 T_{\min }}{T_{\min }+217.9}\right)$

$e_{\mathbb{Q}}=0.611 \exp \left(\frac{17.27 T_{\mathbb{R}}}{T_{\mathbb{d}}+237.3}\right)$

$R_{a}=37.6 d r\left(W_{g} \sin \phi \sin \delta+\cos \phi \cos \delta \sin W_{g}\right)$

$W_{s}=\arccos (-\tan \phi \tan \delta)$

$d r=1+0.033 \cos (0.0172 j)$

$\delta=0.409 \sin (0.0172 j-1.39)$

$l=$ integer $(30.5 M-14.6)$

$N=7.64 W_{s}$

$R_{\beta 1}=0.77(0.25+0.50 \mathrm{n} / \mathrm{N}) R_{\square}-2.45$

$$
\left.\times 10^{-9}\left(\frac{0.9 n}{N}+0.1\right)\left(0.34-0.14 \sqrt{e_{d}}\right)\left(T_{\text {gmax }}+237.3\right)^{4}+\left(T_{\text {min }}+237.3\right)^{4}\right)
$$

$F B C=a+b\left[p\left(0.46 T_{\text {mean }}+8.13\right)\right]$

$$
a=0.0043\left(R H_{\min }\right)-\frac{n}{N}-1.41
$$

$b=0.82-0.0041\left(R H_{\min }\right)+1.07\left(\frac{n}{N}\right)+0.066\left(R H_{\min }\right) \frac{n}{N}-0.0006\left(R H_{\text {ming }}\right) U$

$R H_{\min }=100 \times \frac{e_{\mathbb{Q}}}{e\left(T_{\text {min }}\right)}$

TUTC $=a_{I} \times 0.013 \frac{T_{\text {means }}}{T_{\text {mean }}+15}+\frac{23.8656 R_{g}+50}{\lambda}$

If $R H_{\max } \geq 50 \rightarrow a_{T}=1$

If $R H_{\text {grean }}<50 \rightarrow a_{Y}=1+\frac{50-R H_{\text {Mean }}}{70}$

$R_{g}=0.16 R_{a} \sqrt{T_{\text {gxax }}-T_{\text {ming }}}$

$R H_{\text {mean }}=100 \times \frac{e_{Q d}}{e_{a x}}$

FRM $=-0.3+c\left[\frac{\Delta}{\Delta+\gamma}\right] \frac{R_{g}}{\lambda}$

$c=1.0656-0.0012795 R H_{\text {mean }}+0.044953 \mathrm{~V}-0.0002033 R H_{\text {mean }} U-0.000031508 R H_{\text {mean }}$

$$
-0.0011026 \mathrm{~V}
$$

$P T=\frac{1,26}{\lambda} \times \frac{\Delta}{\Delta+\gamma}\left(R_{R 2}-G\right)$

HS $=0.0023 R_{a}\left(T_{\operatorname{mean}}+17.8\right) \sqrt{T_{\text {max }}-T_{\min }}$

$T W=16 N_{m}\left(\frac{10 T_{\text {mean }}}{l}\right)^{\infty}$

$\alpha=\left(6.75 \times 10^{-7}\right) I^{9}-\left(7.71 \times 10^{-5}\right) I^{2}+\left(1.792 \times 10^{-2}\right) I+0.492$ 


$$
\begin{aligned}
& I=\sum i_{x} \\
& i_{\mathrm{man}}=\left(\frac{T_{\mathrm{mxan}}}{5}\right)^{1.511} \\
& C J H=0.142 C_{T}\left(T_{\text {mean }}-T_{M P}\right) R_{A} \sqrt{T_{\text {max }}-T_{\text {mxim }}} \\
& C_{T}=\frac{1}{45-(Z / 137)+\left(365 /\left(e_{\text {gmax }}-e_{\text {gmin }}\right)\right)} \\
& T_{x}=-2.5-0.14\left(e_{\text {gmax }}-e_{\text {gaxim }}\right)-\frac{Z}{500} \\
& e_{\text {gamax }}=\exp \left(\frac{19.08 T_{\max }+429.41}{T_{\max }+237.3}\right) \\
& e_{\text {gming }}=\exp \left(\frac{19.08 T_{\text {minn }}+429.41}{T_{\text {min }}+237.3}\right)
\end{aligned}
$$

VI.

$\Delta=$ Slope wapour pressure curve $\left(\right.$ KPaf $\left.{ }^{2} \mathrm{C}\right)$

Abbreviations

$R_{\mathrm{n}}=$ Wet radiation at the crop surface $\left(\frac{\text { MI }}{\mathrm{m}^{2} \text { day }}\right)$

$G=$ Soil heat flux density $\left(\frac{M J}{m^{2} \text { day }}\right)$

$\gamma=$ Psychrometric constant $\left(K P a f^{\circ} \mathrm{C}\right)$

$T_{\text {mean }}=$ Mean temperature $\left({ }^{\circ} \mathrm{C}\right)$

$U=$ Wind speed $\left(\frac{m}{g}\right)$

$e_{a}=$ Actwal wapow pressure $[\mathrm{KPa}]$

$\Theta_{d}=$ Dew point wapour pressure $($ KPa)

$P=$ Atmospheric pressure $(K P a)$

$\mathrm{\lambda}=$ Latent heat of waporization $\left(\frac{M J}{K_{g}}\right)$

$z=$ Elewation of alimate stationabowe sen level(m)

$T_{\text {max }}=$ Maximum temperature $\left({ }^{\circ} \mathrm{C}\right)$

$T_{\text {min }}=$ Minimum temperature $\left({ }^{\circ} \mathrm{C}\right)$

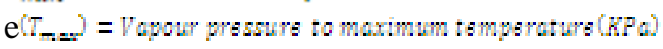

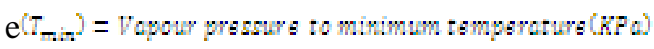

$T_{\mathbb{d}}=$ Dew point temperature $\left({ }^{\circ} \mathrm{C}\right)$

$R_{a}=$ Extrateresterial radiation $\left(\frac{M J}{m^{2} \text { day }}\right)$

dr $=$ Inverse relative distance Earth -5 un

$W_{g}=$ Sunset thour angle $($ rad)

$\phi=$ Latitude(rad)

$\delta$ Solar declination(rad)

$I=$ julian day

$N=$ Avallable duration of sunshine howrs(hr)

$n=$ sunshine hours recorded(hr)

$a_{3} b_{0} p=$ Parameters of FBC equation

$R H_{\text {xim }}=$ Minimum of relative humidity ( $(\%)$

$R_{g}=$ Solar radiation $\left(\frac{\text { MI }}{m^{2} \text { day }}\right)$

$a_{T}=$ Parameter of Ture equation

$R H_{\text {mean }}=$ Mean of relative humidity (\%)

$c=$ Parameter of FRM equation

$\mathbb{N}_{\mathrm{W}} \mathbb{Q}=$ Parameters of TW equation

$\mathrm{I}_{\mathrm{m}}=$ Month heat inder

$I=$ Year heat index

$T_{z^{*}} C_{\mathbb{T}^{*}} R_{A}=$ Parameters of $\mathrm{Cj} H$ equation

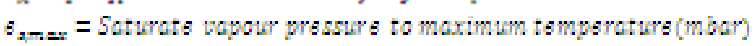

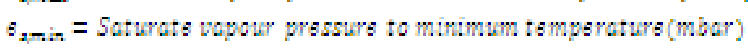




\section{References}

[1] Alexandris, S., P. Kerkides and A. Liakatas, 2006. Daily reference evapotranspiration estimates by the "Copais" approach, Agricultural Water Management, 28(3), pp: 371-386. DOI: http://dx.doi.org/10.1016/j.agwat.2005.08.001

[2] Alexandris, S. and P. Kerkides, New empirical formula for hourly estimations of reference evapotranspiration Agricultural Water Management, 60(3), pp: 157-180. DOI: http://dx.doi.org/10.1016/S0378-3774(02)00172-5

[3] Balaguer, E., A. Palomares, E. Sorie and J.D. Martin-Guerrero, 2008. Predicting service request in support centers based on nonlinear dynamics, ARMA modeling and neural networks. Expert Systems with Applications, 34(1), pp: 665-672. DOI: 10.1016/j.eswa.2006.10.003

[4] Bois, B., P. Pieri, C. Van Leeuwen, L. Wald, F. Huard, J.-P. Gaudillere and E. Saur, 2008. Using remotely sensed solar radiation data for reference evapotranspiration estimation at a daily time step, Agricultural and Forest Meteorology, 148(4), pp: 619-630. DOI: http://dx.doi.org/10.1016/j.agrformet.2007.11.005

[5] Box, G.E.P., G.M., Jenkins, 1976. Series Analysis Forecasting and Control. Prentice-Hall Inc., London.

[6] Casa, R., G. Russell, B. Lo Cascio, 2000. Estimation of evapotranspiration from a field of linseed in central Italy, Agricultural and Forest Meteorology, 104(4), pp: 289-301. DOI: http://dx.doi.org/10.1016/S0168-1923(00)00172-6

[7] Chenoweth, T., K. Dowling, R., Hubata and R. Louis, 2004. Automatic ARMA identification using neural networks and the extended sample autocorrelation function: a reevaluation. Decision Support Systems, 29, pp: 21-30. DOI: http://dx.doi.org/10.1016/S0167-9236(00)00058-0

[8] Chenoweth, T., K. Dowling, R., Hubata, and R. Louis, 2004. Distance and prediction error variance constraints for ARMA model portfolios. International Journal of Forecasting, 20, pp: 41-52. DOI: http://dx.doi.org/10.1016/S0169-2070(03)00006-2

[9] Cryer, D. and J.C. Kung-Sik, 2008. Time Series Analysis: With Applications in R, 2nd Ed. Springer, ISBN: 0387759581

[10] Douglas, E.M., J.M Jacobs, D.M., Sumner and R.L. Ray, 2009. A comparison of models for estimating potential evapotranspiration for Florida land cover types, Journal of Hydrology, 373(3-4), pp: 366-376. DOI: http://dx.doi.org/10.1016/j.jhydrol.2009.04.029

[11] Granger, R.J., 2000. Satellite-derived estimates of evapotranspiration in the Gediz basin, Journal of Hydrology, 229(1-2), pp: 7076. DOI: http://dx.doi.org/10.1016/S0022-1694(99)00200-0

[12] Kadlec, R.H., 2006. Water temperature and evapotranspiration in surface flow wetlands in hot arid climate, Ecological Engineering, 26(4), pp: 328-340. DOI: http://dx.doi.org/10.1016/j.ecoleng.2005.12.010

[13] Kang, Sh., B. Gu, T. Du and J. Zhang, 2003. Crop coefficient and ratio of transpiration to evapotranspiration of winter wheat and maize in a semi-humid region, Agricultural Water Management, 59(3), pp: 239-254. DOI: http://dx.doi.org/10.1016/S03783774(02)00150-6

[14] Kim, S. and H.S., Kim, 2008. Neural networks and genetic algorithm approach for nonlinear evaporation and evapotranspiration modeling, Journal of Hydrology, 351(3-4), pp: 299-317. DOI: http://dx.doi.org/10.1016/j.jhydrol.2007.12.014

[15] Ludlow, J. and W. Enders, 2000. Estimating non-linear ARMA models using Fourier Coefficients, International Journal of Forecasting, 16(3), pp: 333-347.

[16] M. Baareh, A.K., A. F. Sheta and Kh. Al Khnaifes, 2006, Forecasting River Flow in the USA: A Comparison between AutoRegression and Neural Network Non-Parametric Models, Journal of Computer Science, 2 (10), pp: 775-780.

[17] Mohammadi, K., H.R. Eslami and S. Dayyani Dardashti, 2005. Comparison of Regression ARIMA and ANN Models for Reservoir Inflow Forecasting using Snowmelt Equivalent (A Case Study of Karaj), Journal of Agriculture Science Technology, 7, pp. 17-30.

[18] Mohammadi, K., H.R. Eslami and R. Kahawita, 2006. Parameter estimation of an ARMA model for river flow forecasting using goal programmin, Journal of Hydrology, 331 (2), pp: 293-299, DOI: 10.1016/j.jhydrol.2006.05.017

[19] Pereira, A.R., (2004). The Priestley-Taylor parameter and the decoupling factor for estimating reference evapotranspiration, Agricultural and Forest Meteorology, 125(3-4), pp: 305-313. DOI: http://dx.doi.org/10.1016/j.agrformet.2004.04.002

[20] See, L., and R.J. Abrahat, 2001. Multi-model data fusion for hydrological forecasting, Computers \& Geosciences, 27, pp: 987-994, DOI: http://dx.doi.org/10.1016/S0098-3004(00)00136-9

[21] Silva, D., F. J. Menz and E. Varas, (2010). Estimating reference evapotranspiration (ETo) using numerical weather forecast data in central Chile, Journal of Hydrology, 382(1-4), pp: 64-71. DOI: http://dx.doi.org/10.1016/j.jhydrol.2009.12.018

[22] Srinivas, V.V., and K. Srinivasan, 2000. Post-blackening approach for modeling dependent annual streamflows, Journal of Hydrology, 230, pp: 86-126, DOI: http://dx.doi.org/10.1016/S0022-1694(00)00168-2

[23] Sumner, D.M. and J.M. Jacobs, 2005. Utility of Penman-Monteith, Priestley-Taylor, reference evapotranspiration, and pan evaporation methods to estimate pasture evapotranspiration, Journal of Hydrology, 308(1-4), pp: 81-104. DOI: http://dx.doi.org/10.1016/j.jhydrol.2004.10.023

[24] Toth, E., A. Brath, and A. Montanari, 2000. Comparison of short-term rainfall predication models for real-time flood forecasting, Journal of Hydrology, 239, pp: 132-147, DOI: http://dx.doi.org/10.1016/S0022-1694(00)00344-9

[25] Valipour, M., M.E., Banihabib and S.M.R., Behbahani, 2012. Journal of Mathematics and Statistics.

[26] Wei, W.W.S., 1990. Time Series Analysis: Univariate and Multivariate Methods, 2nd Ed. Addison Wesley, ISBN: 0321322169

[27] Xiong, L. and K. M. O'connor, 2002, Comparison of four updating models for real-time river flow forecasting, Hydrological Sciences-Journal-des Sciences Hydrologiques, 47(4), pp: 621-639.

[28] Xu, Ch., L., Gong, T., Jiang, D., Chen and V.P. Singh, Analysis of spatial distribution and temporal trend of reference evapotranspiration and pan evaporation in Changjiang (Yangtze River) catchment, 2006. Journal of Hydrology, 327(1-2), pp: 8193. DOI: http://dx.doi.org/10.1016/j.jhydrol.2005.11.029

[29] Yin, Y., Sh., Wu, D. Zheng and Q., Yang, 2008. Radiation calibration of FAO56 Penman-Monteith model to estimate reference crop evapotranspiration in China, Agricultural Water Management, 95(1), pp: 77-84. DOI: http://dx.doi.org/10.1016/j.agwat.2007.09.002

[30] Yu, X., and S. Liong, 2006. Forecasting of hydrologic time series with ridge regression in feature space, Journal of Hydrology, 332, pp: 290- 302, DOI: http://dx.doi.org/10.1016/j.jhydrol.2006.07.003

[31] Zhou, M.C., H., Ishidaira, H.P., Hapuarachchi, J., Magome, A.S., Kiem and K., Takeuchi, Estimating potential evapotranspirati on using Shuttleworth-Wallace model and NOAA-AVHRR NDVI data to feed a distributed hydrological model over the Mekong River basin, Journal of Hydrology, 327(1-2), pp: 151-173. DOI: http://dx.doi.org/10.1016/j.jhydrol.2005.11.013 